\title{
Erratum to: Charged shell supported by a phantom energy
}

A. Eid

Received: 20 March 2014 / Accepted: 20 March 2014 / Published online: 26 March 2014

(C) Springer Science+Business Media Dordrecht 2014

Erratum to: Astrophys Space Sci (2013) 345: 203-207

DOI 10.1007/s10509-013-1360-2

In the affiliation of the article the University name should read:

Al Imam Mohammad Ibn Saud Islamic University (IMSIU)

The online version of the original article can be found under doi:10.1007/s10509-013-1360-2.

A. Eid $(\varangle)$

Department of Physics, Collage of Science, Al Imam Mohamed

Ibn Saud Islamic University, Riyadh, KSA

e-mail: aeid06@yahoo.com 